\title{
Concordance between physiotherapists and physicians for care of patients with musculoskeletal disorders presenting to the emergency department
}

E. Matifat ${ }^{1,2}$, K. Perreault ${ }^{3,4}$, J.-S. Roy ${ }^{3,4}$, A. Aiken ${ }^{5}$, E. Gagnon², M. Mequignon ${ }^{1,6}$, V. Lowry ${ }^{1,7}$, S. Décary ${ }^{1}$, B. Hamelin², M. Ambrosio ${ }^{8}$, N. Farley ${ }^{7,8}$, D. Pelletier ${ }^{9}$, L. Carlesso ${ }^{1,10}$ and F. Desmeules ${ }^{1,7^{*}}$

\begin{abstract}
Background: Overcrowding in emergency departments (ED) is a major concern worldwide. To answer increasing health care demands, new models of care including advanced practice physiotherapists (APP) have been implemented in EDs. The purpose of this study was to assess diagnostic, treatment and discharge plan concordance between APPs and ED physicians for patients consulting to the ED for minor musculoskeletal disorders (MSKD).

Methods: Patients presenting to two EDs in Montréal (Canada) with a minor MSKD were recruited and independently assessed by an APP and ED physician. Both providers had to formulate diagnosis, treatment and discharge plans. Cohen's kappa ( $K$ ) and Prevalence and Bias Adjusted Kappas (PABAK) with associated $95 \% \mathrm{Cl}$ were calculated. Chi Square and t-tests were used to compare treatment, discharge plan modalities and patient satisfaction between providers.
\end{abstract}

Results: One hundred and thirteen participants were recruited, mean age was $50.3 \pm 17.4$ years old and $51.3 \%$ had an atraumatic MSKD. Diagnostic inter-rater agreement between providers was very good $(\mathrm{K}=0.81 ; 95 \% \mathrm{Cl}$ : 0.72-0.90). In terms of treatment plan, APPs referred significantly more participants to physiotherapy care than ED physicians $(\mathrm{K}=0.27$; PABAK $=0.27 ; 95 \% \mathrm{Cl}: 0.07-0.45 ; p=0.003)$. There was a moderate inter-rater agreement $(K=0.46$; PABAK $=0.64 ; 95 \% \mathrm{Cl}: 0.46-0.77)$ for discharge plans. High patient satisfaction was reported with no significant differences between providers $(p=0.57)$.

Conclusion: There was significant agreement between APPS and ED physicians in terms of diagnosis and discharge plans, but more discrepancies regarding treatment plans. These results tend to support the integration of APPs in ED settings, but further prospective evaluation of the efficiency of these types of models is warranted.

Keywords: Physiotherapist, Emergency department, Primary care, Musculoskeletal disorders

\footnotetext{
*Correspondence: f.desmeules@umontreal.ca

${ }^{1}$ Maisonneuve-Rosemont Hospital Research Center, University of Montreal

Affiliated Research Center, Montréal, Québec, Canada

${ }^{7}$ School of Rehabilitation, Faculty of Medicine, University of Montréal,

Montréal, Québec, Canada

Full list of author information is available at the end of the article
}

(c) The Author(s). 2019 Open Access This article is distributed under the terms of the Creative Commons Attribution 4.0 International License (http://creativecommons.org/licenses/by/4.0/), which permits unrestricted use, distribution, and reproduction in any medium, provided you give appropriate credit to the original author(s) and the source, provide a link to the Creative Commons license, and indicate if changes were made. The Creative Commons Public Domain Dedication waiver (http://creativecommons.org/publicdomain/zero/1.0/) applies to the data made available in this article, unless otherwise stated. 


\section{Background}

Overcrowding in emergency departments (ED) is a major concern in healthcare systems worldwide. Each year, there are almost 16 million visits made to Canadian EDs [1]. Recent reports indicate that Canada is among the countries with the longest ED waiting times. Indeed, the percentage of people waiting four hours or more in the ED is higher in Canada compared to other countries, such as Australia and the United Kingdom [2]. This situation is a major concern, especially in light of the aging population and increases in the prevalence of chronic diseases [3]. Patients presenting to EDs with minor musculoskeletal disorders (MSKD), such as tendinopathy, back pain or sprains represent more than $25 \%$ of all ED visits [4].

Several initiatives that have been implemented worldwide to reduce waiting times and improve care efficiency often include the extension of the scope of practice of non-physician health care providers $[5,6]$. In the last few decades, physiotherapists have seen their scope of practice extended in various settings, such as rheumatology, orthopaedics and primary care clinics. As they are regulated health care practitioners with extensive training in this field, physiotherapists provide safe and effective care for patients with various MSKD and refer patients with conditions that are outside their scope of practice to other practitioners [4]. Often referred to as advanced practice physiotherapy (APP) models, the new roles of physiotherapists include enhancement of their responsibilities, such as: direct access to patient traditionally seen by a physician first, ability to make diagnoses, triaging surgical patients, ordering imaging or laboratory tests and prescribing certain medications [711]. In Australia and the United Kingdom, APPs have also been implemented in EDs and have been shown to improve access and quality of care for patients with minor MSKD [12], while providing safe and effective care and retaining high patients' satisfaction [13-17]. The current literature on APP in EDs indicate that they can be a viable option to improve access to care for patients with MSKD [13, 16-19]. Nevertheless, only a limited amount of studies in EDs has examined the benefits and safety of these models and none have assessed diagnosis and management concordance between physiotherapists and physicians $[16,17,19,20]$. The evaluation of the potential benefits of such models is highly context-dependent and the evaluation of these models is warranted to support further development and implementation of APP in EDs.

The objectives of the current study were to determine the diagnostic interrater reliability between ED physicians and APPs, as well as to assess treatment and discharge plan concordance, including medical imaging requests and medication recommendations, and patient satisfaction between both healthcare providers in this new model for ED patients with minor MSKD.

\section{Methods \\ Settings}

Patients were recruited from April 2017 to July 2018 from two EDs in Montréal (Canada).

\section{Physiotherapists and physician in the participating emergency departments}

The three physiotherapists participating to this study were already working in both recruitment sites and were already involved in the ED. They had previous experience working in theses EDs as secondary contact providers, with experience ranging from 2 years to 14 years, and had experience for care of patients with MSKD, in both an inpatient and outpatient settings, with experience ranging from 2 to 29 years. Thirty-seven ED physicians participated in the current study. In the province of Québec, APP models of care include direct access to patients in hospital settings. Ability to prescribe $\mathrm{x}$-rays is soon to be allowed under new regulation.

\section{Participants}

All patients presenting to the ED and that were identified by the triage nurse as having a possible minor MSKD or identified on the ED triage list by a research assistant as having a possible minor MSKD were considered for this study on days that recruitment was taking place. Other inclusion criteria were: 1) 18 years or older; 2) legally able to consent; 3) able to understand/speak French or English; 4) resident of the province of Quebec and beneficiary of the provincial health insurance coverage (RAMQ). Exclusion criteria were patients having: 1) been previously treated by one of the APPs or physicians involved in this study; 2) an injury resulting from significant trauma (such as major motor vehicle accident) or a major musculoskeletal injury, such as open fracture or open wound; 3) obvious red flags, such as progressing neurological deficits or infection related signs or symptoms; 4) diagnosed inflammatory arthritis and 5) other active/unstable non-musculoskeletal conditions, such as pulmonary, cardiac, digestive or psychiatric conditions.

\section{Data collection}

Prior to being seen by the APP or the ED physician, eligible participants completed a structured questionnaire with the research assistant where they provided anthropometric data as well as data on their education, employment, household income, household living status, and information on clinical variables such as the joint affected, the reason for consulting, the history of the lesion, the duration of their symptoms, the use of a walking aid and the presence of any comorbidities. 
Participants also completed the acute 36-item Short Form Survey Questionnaire (SF-36) to assess their health-related quality of life and, depending on the affected body region, the relevant standardized selfreported disability questionnaires among the Neck Disability Index (NDI), the Oswestry Disability Index (ODI) for spine disorders, the Disability of the Arm, Shoulder and Hand (DASH) questionnaire for upper extremity disorders or the Lower Extremity Functional Scale (LEFS) for lower extremity disorders. The SF-36 has been shown to be valid, reliable and responsive to change with various populations with MSKD [21-23]. The NDI, ODI, DASH and LEFS are standardized selfreported disability questionnaires that are validated, reliable and responsive to change [24-30].

The participants were then independently assessed by both providers. The clinical evaluation and specific physical tests used by both providers to complete the evaluation were not standardized, as so they could use any evaluation techniques or physical tests they felt appropriate to reach a diagnosis. After the assessment, the physiotherapist and the ED physician each independently completed a standardized evaluation form where they indicated the primary, and secondary if relevant, diagnoses, their request for additional medical imaging necessary to provide appropriate care or to confirm or exclude a diagnosis, their detailed treatment plan, including conservative treatment options, referral to other providers (such as orthopedics) and medication recommendations, and their discharge plan from the ED (Appendix). Due to feasibility considerations, the physiotherapist always completed the assessment before the ED physician. A research assistant ensured that the physiotherapist and the ED physician were blinded to each other's diagnosis, treatment plan and discharge plan until both providers had completed the evaluation and had filled out the standardized form. Also, physiotherapists were asked to not initially disclose information on their diagnosis or management plan to the patients to avoid any influence on the ED physician's diagnosis. Both providers had access to the patient's medical file, including any previous medical imaging results available. If medical imaging was judged necessary to specify either the diagnosis or treatment plan, providers were asked to specify which type of imaging was needed. Within their treatment plans, providers were also asked to specify the relevant conservative treatment options for the patient from among the following options: 1) advice and education, 2) walking aids/orthosis, 3) home exercises or 4) specify other options. They were also asked to specify if supervised physiotherapy follow-up was relevant and any medication recommendations, either prescription or non-prescription. Regarding the ED discharge plan, providers needed to select between three options: 1) hospitalization, 2) discharge home without medical follow-up or 3) discharge with a medical follow-up (family physician, specialist as an outpatient, other). The time in minutes for each provider to complete the evaluation was recorded. To record any change in the patient's condition that would modify the ability for the second provider to make a diagnosis, participants were asked to complete a form where they specified if their pain level had changed after the first assessment (1- no change in condition 2- pain is slightly higher; 3 - pain is moderately higher; 4- pain is significantly higher). To ensure that patients' conditions were similar for both evaluations, patients were excluded from the study if pain was recorded as significantly higher after the initial assessment by the physiotherapist.

After assessment by both the physiotherapist and the ED physician, patients completed before discharge a modified version of the 9-item Visit-Specific Satisfaction Questionnaire (VSQ-9) in relation to each provider they had seen [6, 31, 32]. Participants were informed that answers would remain confidential. The questionnaire included 7 questions rated on a 1 to 5 scale $(1=$ excellent and $5=$ poor) and relates to satisfaction with care received, including perceived quality of assessment, personal manner of the provider and quality of advice and information received.

\section{Analyses}

Descriptive statistics were used to describe the patients' characteristics. Cohen's kappa ( $\mathrm{k}$ ) as well as Prevalence and Bias Adjusted Kappas (PABAK) with associated 95\% confidence intervals (95\% CI) were calculated for diagnosis concordance, medical imaging requests, treatment plan, including recommendation for medication and physiotherapy care, and discharge plans. Interpretation of inter-rater agreement was made according to the following scale in which $0-0.20$ is weak, $0.21-0.40$ slight agreement, $0.41-0.60$ moderate agreement, $0.61-0.80$ good agreement, $0.81-0.90$ very good agreement and > 0.90 excellent agreement [33, 34]. Due to the multiple possible diagnoses as well as the different nomenclature sometimes used by physicians and physiotherapists, diagnoses were put into diagnostic categories based on the assessment by two independent reviewers to establish if diagnoses were concordant. The main categories were soft tissue disorders, spinal disorders, articular disorders, fracture or luxation and neurological disorders or other disorders. An independent third rater was used if consensus could not be reached. Ultimately the patient was managed according to the physician directives as the study only assessed the potential ability of the physiotherapist to manage autonomously these types of cases. In addition, Chi Square tests were used to compare treatment and discharge plan modalities and 
student $\mathrm{t}$-tests were used to compare patient satisfaction. Analyses were preformed using SPSS version 25 (SPSS Inc., Chicago) and R version 3.4.3.

\section{Sample size}

We calculated the sample size with an expected kappa inter-rater agreement of at least $\mathrm{K}=0.8$, a raw proportion of agreement of $80 \%$ and power of $80 \%$ [35]. A minimum sample size of 75 participants was required, but to insure representability of the sample and to take into account the multiple MSKD encountered in an ED setting, we aimed to recruit a sample size of at least 100 participants.

\section{Ethics}

All participants signed a consent form prior to entering the study. This study was approved by the Research Ethics Boards of both hospitals.

\section{Results}

\section{Participants}

One hundred and twenty-five potential participants were identified after initial assessment at triage during recruitment periods, 70 in the first site and 55 in the second site. Eight declined participation to this study and the reasons were: fatigue $(n=1)$, pain was too severe $(n=2)$, was presenting to the ED to have a joint injection $(n=$ $1)$, only wanted to see a physician $(n=2)$ and did not want to grant access to their medical file $(n=2)$. Four patients were excluded: two patients had obvious red flags (infection for both), one left after being assessed by only one out of two providers and one participant was recruited but afterward none of the providers were available for the assessments. A total of 113 participants were included in the analyses (Fig. 1).

\section{Subjects' characteristics}

Participants' characteristics are included in Table 1. Subjects had a mean age of 50.3 years (SD: 17.4 ) with $49.6 \%$

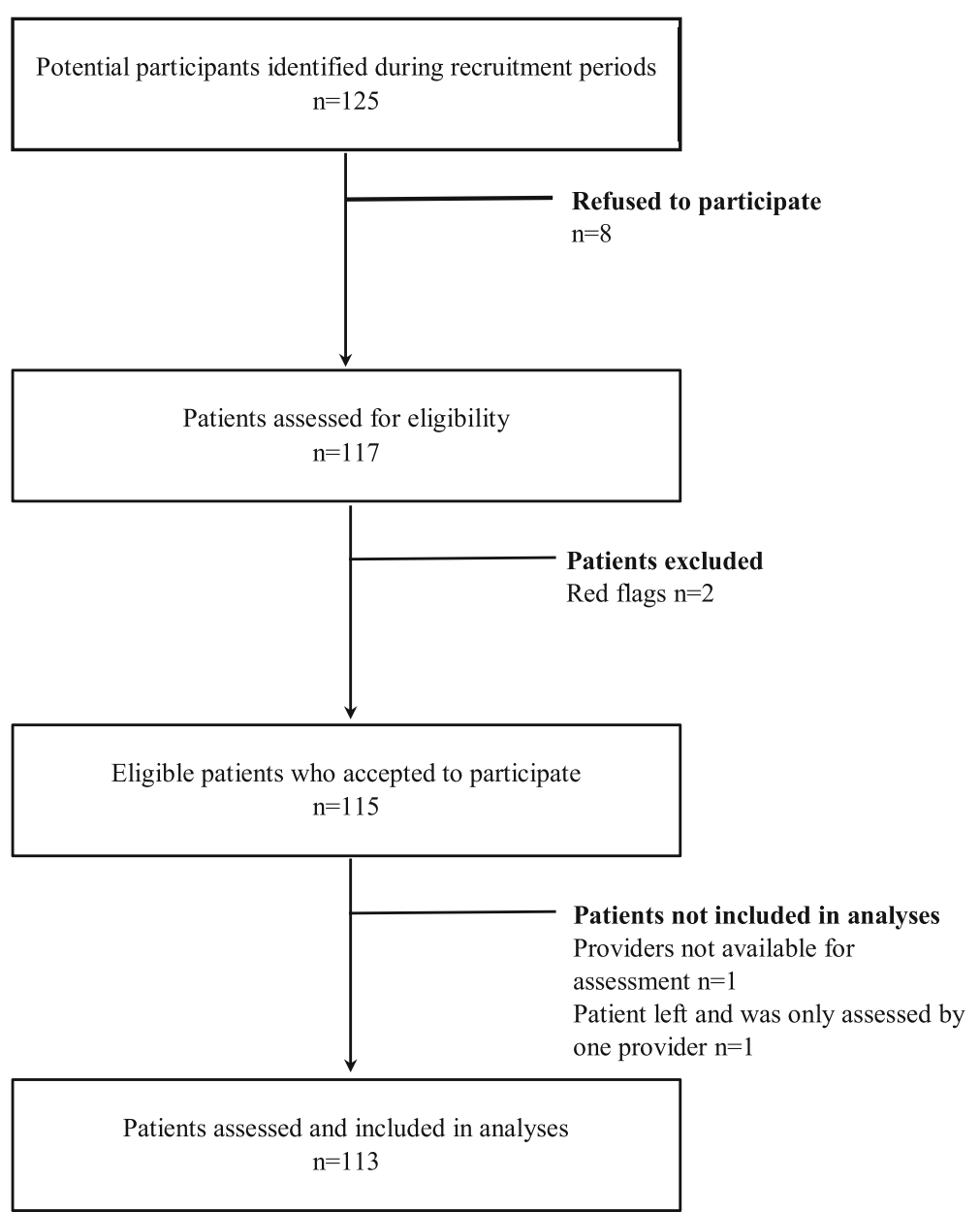

Fig. 1 Flowchart of study participants 
Table 1 Characteristics of participants $(n=113)$

\begin{tabular}{lll}
\hline Characteristics & $\mathrm{n}(\%)$ & $\begin{array}{l}\text { Mean } \\
(\mathrm{SD})\end{array}$ \\
\hline Age & $50.3(17.4)$ \\
Gender & & \\
Male & 56 \\
& $(49.6)$ \\
Female & 57 \\
& $(50.4)$ \\
Education & \\
High school or less & 50 \\
& $(44.2)$ \\
College or university & 63 \\
& $(55.8)$ \\
Household income $(n=86)$ & \\
$0-29,999 \$$ & 28 \\
$30,000 \$$ - 59,999\$ & $(32.6)$ \\
$60,000 \$$ and up & 31 \\
& $(36.0)$ \\
\hline
\end{tabular}

Type of injury/disorder

Traumatic 55

Atraumatic $\quad 58$

(51.3)

Using a walking aid $(n=111) \quad 18$

(16.2)

Number of comorbidities per participant 1(1.2)

36-item Short Form Survey score (\%)- Acute version (SF-36) $(n=104)$

Physical Component

$38.3(10.4)$

Mental Component

$44.3(13.3)$

Lower Extremity Functional Scale (LEFS) (/80) ( $n=$

52)

Oswestry Disability Index (ODI) (\%) ( $n=22)$

$23.3(17.3)$

$54.8(0.2)$

Disabilities of the Arm, Shoulder and Hand (quick DASH)

(/100) $(n=27)$

Neck Disability Index (NDI) (/50) $(n=3)$

SD standard deviation

of men and $50.4 \%$ of women. With some patients presenting disorders in more then one body region, $29 \%$ of patients had an upper limb disorder, 43\% a lower limb disorder, $5 \%$ a cervical spine disorder, $4 \%$ a thoracic disorder and $19 \%$ a lumbar disorder. Most patients (51.3\%) had an atraumatic disorder. Participants had a mean score of $38.3 \%(\mathrm{SD} \pm 10.4)$ on the Physical Component Scale and $44.3 \%(\mathrm{SD} \pm 13.3)$ on the Mental Component
Scale of the acute version of the SF-36, indicating fairly impaired health-related quality of life. In terms of the various self-reported disability questionnaires based on the affected body regions, the mean scores were: LEFS 23.3 (SD \pm 17.3 ), ODI 54.8\% (SD \pm 0.2 ), quick-DASH 44.2 $(\mathrm{SD} \pm 29.3)$ and NDI $25.7(\mathrm{SD} \pm 1.5)$.

\section{Diagnostic agreement between ED physicians and APPs and medical imaging}

Overall, raw agreement regarding diagnosis between ED physicians and APPs was $87 \%$, based on both primary and secondary diagnoses. A secondary diagnosis was present for $54 \%$ of patients $(61 / 113)$. Inter-rater diagnosis agreement was very good $(\mathrm{K}=0.81 ; 95 \% \mathrm{CI}$ : $0.72-$ 0.90) (Table 2).

In terms of requests for medical imaging, APPs and ED physicians ordered almost the same amount of imaging tests (respectively for $71 \%$ and $70 \%$ of participants, $p=0.884$ ). Raw agreement proportion was $80 \%$ and inter-rater agreement was moderate (Kappa $=0.51$; PABAK $=0.59 ;$ 95\% CI: 0.42-0.73) (Table 3).

\section{Treatment and discharge plans}

In terms of treatment plan, APPs referred significantly more participants to physiotherapy care than ED physicians (50\% compared to $34 \%, p=0.018)$. Raw agreement was $64 \%$ and overall there was only slight agreement between providers $(\mathrm{Kappa}=0.27$; $\mathrm{PABAK}=0.27$; $95 \% \mathrm{CI}$ : 0.07-0.45) (Table 3). In terms of medication, nonprescription and prescription drugs were analysed separately. APPs recommended more non-prescription drugs than ED physicians, but there was no significant difference (50\% compared to $39 \%, p=0.126)$. Raw agreement proportion was $61 \%$ and only slight agreement between providers was observed (Kappa $=0.22 ;$ PABAK $=0.22$; 95\% CI: 0.02-0.41) (Table 3). In terms of prescription drugs, ED physicians recommended them significantly more than APPs (70\% compared to $47 \%, p<0.001)$. Raw agreement proportion was $66 \%$ and overall only slight agreement was obtained between raters (Kappa $=0.33$; PABAK $=0.31 ; 95 \%$ CI: 0.11-0.49) (Table 3).

In terms of discharge plans from the ED, providers were asked to specify if the patient needed any type of medical follow-up upon ED discharge (No follow-up, hospitalisation, referral to a specialist, return to general practitioner or other medical follow-up). Twenty-one percent of patients had no medical follow-up upon ED discharge, $34 \%$ were sent back to their family physician, $43 \%$ were referred to an outpatient speciality clinic and

Table 2 Diagnostic Agreement between emergency department physicians and advanced practice physiotherapists $(n=113$ )

\begin{tabular}{llccc}
\hline & Raw agreement proportion (\%) & Cohen's Kappa & $95 \%$ Cl & $p$ value \\
\hline Diagnostic Agreement & $98 / 113(87)$ & 0.81 & 0.72 to 0.90 & $p<0.001$ \\
\hline
\end{tabular}


Table 3 Differences in proportion and concordance for treatment and discharge plans between advanced practice physiotherapists and ED physicians

\begin{tabular}{|c|c|c|c|c|c|c|c|c|}
\hline & $\begin{array}{l}\text { Recommended by } \\
\text { MD (\%) }\end{array}$ & $\begin{array}{l}\text { Recommended by } \\
\operatorname{APP}(\%)\end{array}$ & $\begin{array}{l}\text { Chi-square } \\
\text { test }\end{array}$ & $\begin{array}{l}p \\
\text { value }\end{array}$ & $\begin{array}{l}\text { Raw agreement } \\
\text { proportion (\%) }\end{array}$ & $\begin{array}{l}\text { Cohen's } \\
\text { Kappa }\end{array}$ & PABAK & $\begin{array}{l}95 \% \\
\mathrm{Cl}\end{array}$ \\
\hline Medical imaging requests $^{\square}$ & 79/113 (70) & $80 / 113(71)$ & 0.021 & 0.884 & $90 / 113(80)$ & 0.51 & 0.59 & $\begin{array}{l}0.42 \text { to } \\
0.73\end{array}$ \\
\hline Physiotherapy care referral ${ }^{\S}$ & 36/107 (34) & $53 / 107(50)$ & 5.559 & ${ }^{*} 0.018$ & 68/107 (64) & 0.27 & 0.27 & $\begin{array}{l}0.07 \text { to } \\
0.45\end{array}$ \\
\hline \multicolumn{9}{|l|}{ Medication recommendations ${ }^{*}$} \\
\hline Non-prescription drugs & 41/105 (39) & $52 / 105(50)$ & 2.335 & 0.126 & $64 / 105(61)$ & 0.22 & 0.22 & $\begin{array}{l}0.02 \text { to } \\
0.41\end{array}$ \\
\hline Prescription drugs & 73/105 (70) & 49/105 (47) & 11.267 & ${ }^{*} 0.001$ & 69/105 (66) & 0.33 & 0.31 & $\begin{array}{l}0.11 \text { to } \\
0.49\end{array}$ \\
\hline $\begin{array}{l}\text { Discharge Plan (need for } \\
\text { medical follow-up) }\end{array}$ & 78/99 (79) & 78/99 (79) & 0.000 & 1.000 & $81 / 99(82)$ & 0.46 & 0.64 & $\begin{array}{l}0.46 \text { to } \\
0.77\end{array}$ \\
\hline
\end{tabular}

MD ED physicians, APP advanced practice physiotherapist, ${ }^{\square} n=113,{ }^{5} n=107,{ }^{*} n=105,{ }^{\ddagger} n=99,{ }^{*}$ Significant value $(p<0.05)$

$2 \%$ were hospitalized. There was significant agreement between providers with an $82 \%$ raw agreement proportion and a moderate inter-rater agreement (Kappa $=$ 0.46; PABAK $=0.64 ; 95 \%$ CI: 0.46-0.77) (Table 3).

\section{Evaluation length and patient satisfaction}

Overall, ED physicians had significantly shorter overall consultation times (mean $5.8 \mathrm{~min} ; \mathrm{SD} \pm 4.2$ ) than APPs (mean $13.5 \mathrm{~min} ; \mathrm{SD} \pm 8.6) \quad(p<0.001)$. There were no significant differences between providers in terms of patients' satisfaction with received care, with both providers obtaining high satisfaction scores $(p=0.57)$ (Table 4).

\section{Discussion}

Since physiotherapists and APPs are being integrated in ED teams worldwide, it is crucial to demonstrate their expertise in this role. Overall, we observed that when it comes to the care for ED patients with minor MSKD, there is significant agreement between APPs and ED physicians in terms of diagnosis and discharge plans, but there is much more variability in terms of treatment plans.

Making the right diagnosis is essential to ensure appropriate care and proper discharge plans for patients with MSKD. Our study is the first to specifically assess diagnosis, treatment and discharge concordance in the ED for patients with MSKD. Previous studies in other settings, such as outpatient orthopedic clinics, have shown equivalent ability between orthopedic surgeons and APPs in terms of diagnosis of common MSKD disorders $[6,36]$. The results of our study show significant concordance between providers in terms of diagnosis. There were discrepancies between APPs and ED physicians in only $15 / 113$ cases. It is important to specify that the ED physician's diagnosis was considered as the reference standard, but we cannot exclude the possibility that the ED physician's diagnosis might have been inaccurate in some cases and therefore, the lack of agreement for those 15 cases might not necessarily be due to an inaccurate diagnosis by the APPs [37, 38].

In terms of requests for medical imaging, both providers ordered about the same amount of imagery and obtained a raw agreement proportion of $80 \%$ with a moderate agreement. These numbers indicate that APPs do not order more medical imagery than ED physicians, which is similar to findings in other studies $[6,39]$. The next step would be to verify the appropriateness of those imaging ordering, since this was not the main objective of this study.

In terms of treatment plans, there was divergence between both types of providers. ED physicians recommended more prescription drugs than non-prescription drugs for minor MSKD. The opposite result was found for APPs. This could reflect the fact that physiotherapists have limited prescribing rights currently in Québec and also that this topic is not covered in detail in entry level physiotherapy education. Looking more closely at

Table 4 Comparison between evaluation length and patient satisfaction for emergency department physicians and advanced practice physiotherapists

\begin{tabular}{|c|c|c|c|c|c|c|}
\hline & Mean value MD (SD) & Mean value APP (SD) & Mean difference (SD) & $95 \% \mathrm{Cl}$ & Student $t$-test & $p$ value \\
\hline$\overline{\text { Evaluation length }(\mathrm{min})^{\square}}$ & $5.8(4.2)$ & $13.5(8.6)$ & $-7.7(0.9)$ & -9.5 to -5.9 & -8.5 & $<0.001$ \\
\hline Patient satisfaction $\S$ & $86.1 \%(18.6)$ & $87.6 \%(16.3)$ & $1.5 \%(2.6)$ & -3.6 to 6.6 & 0.58 & 0.57 \\
\hline
\end{tabular}

$M D$ emergency department physician, $A P P$ advanced practice physiotherapist, $S D$ standard deviation

${ }^{\square} n=110,{ }^{\S} n=91$ 
the types of prescription drugs recommended by ED physicians, we found that almost one third (32\%) of the patients for which a prescription drug was recommended were for opioids (results not shown). These numbers echo with the fact that Canada has already been identified as the country with the second-largest rate of opioids' consumption worldwide [40]. Recent studies have demonstrated that opioids are usually not recommended as the first-line go to for treatment of MSKD pain, but that nonopioid medications and multimodal approaches (including physiotherapy) should be tried first [41]. There was a lot of missing information within APPs' medication recommendations, as where they would mention a need for a prescription drug but without specifying which type, thus it is not possible to see the opioids recommendation rates with APP care in this study. This should be assessed in future studies.

We found significant differences and only slight agreement between providers for rates of referral for physiotherapy care. APPs referred significantly more to physiotherapy care than the ED physicians. Since physiotherapy care has been shown to be an effective treatment option for patients with MSKD, it is surprising that the agreement for physiotherapy care was only minimal. We believe that the fact that physiotherapy care is not covered by the national health coverage in Québec, if provided outside formal public institutions, affected the rates of referral to physiotherapy care by physicians, even more so since access to public physiotherapy has already been found to be limited [42]. ED physicians mentioned informally after the study that they often hesitate to refer to physiotherapy care since they know that a significant portion of the population does not have access to services within the public system and does not have insurance or the resources to pay for physiotherapy care in the private sector.

Another key aspect of ED practice is the discharge plan from the emergency department. Our results show that there was significant concordance between providers in terms of discharge plans from the ED. This shows that in terms of need for medical follow-up upon ED discharge, both providers tend to agree. Only two patients were identified by ED physicians as needing hospitalization for their current disorders. One presented with a suspected tibial plateau fracture with important associated disabilities and the other one a suspected pulmonary neoplasia or vascular pathology. In both cases, the physiotherapist also identified the need for a hospitalization to seek further investigations or treatments. These results show that APPs tend to recommend the same type of discharge plans compared to ED physicians, thus being able to identify the patients who require a medical follow-up upon ED discharge or need immediate medical attention.
Finally, we found no significant differences in terms of patient satisfaction with received care between providers, with both obtaining high satisfaction rates. This is similar to what was found in previous studies assessing ED physiotherapy care, with satisfaction rates being either similar with ED physiotherapy care compared to usual care or even higher with ED physiotherapy care [13, 14, 16-18].

\section{Strengths and limitations}

This study is the first available regarding ED physiotherapy care in Canada and is also the first to assess concordance between ED physicians and physiotherapists in this setting. This study had a multicenter design with a significant number of participants (113) with various injuries and disorders, and also a large number of providers (2 EDs, 3 APPs and 37 ED physicians) which increases the generalization of our findings. The APPs already worked in the participating EDs and had extensive training and experience. Therefore, the results of this study could be different if physiotherapists with lesser training and experience were involved. Formal standardisation of required competences and training is certainly warranted if these models of care are to be expanded.

This study also had a cross-sectional design with no prospective data collection and did not include assessment of the efficacy or the efficiency of such ED models of care. The highest level of evidence for this model of care would have been obtained through a randomized controlled trial (RCT), but since this APP model of care in EDs is still emerging, we believe that our study model was warranted at this stage and is a first step to validate APP expertise in the ED. With the increased implementation of physiotherapy care models in EDs, future studies should include a prospective RCT that will allow evaluation of the efficacy as well as the cost-effectiveness of such models of care.

\section{Conclusion}

Significant concordance in terms of diagnosis and discharge plans was found between APPs and ED physicians for patients with MSKD presenting to the ED. There were more discrepancies between healthcare providers in terms of treatment plans with APPs recommending more physiotherapy care and less prescription drugs than ED physicians. Both providers obtained high satisfaction rates. Future studies should include prospective designs, such as an RCT, and should evaluate the financial impacts, in terms of direct and indirect costs, of these type of models in ED.

Overall, these new APP models of care can be a key solution to improving access to care in Canada, especially for patients with MSKD. 


\section{Appendix}

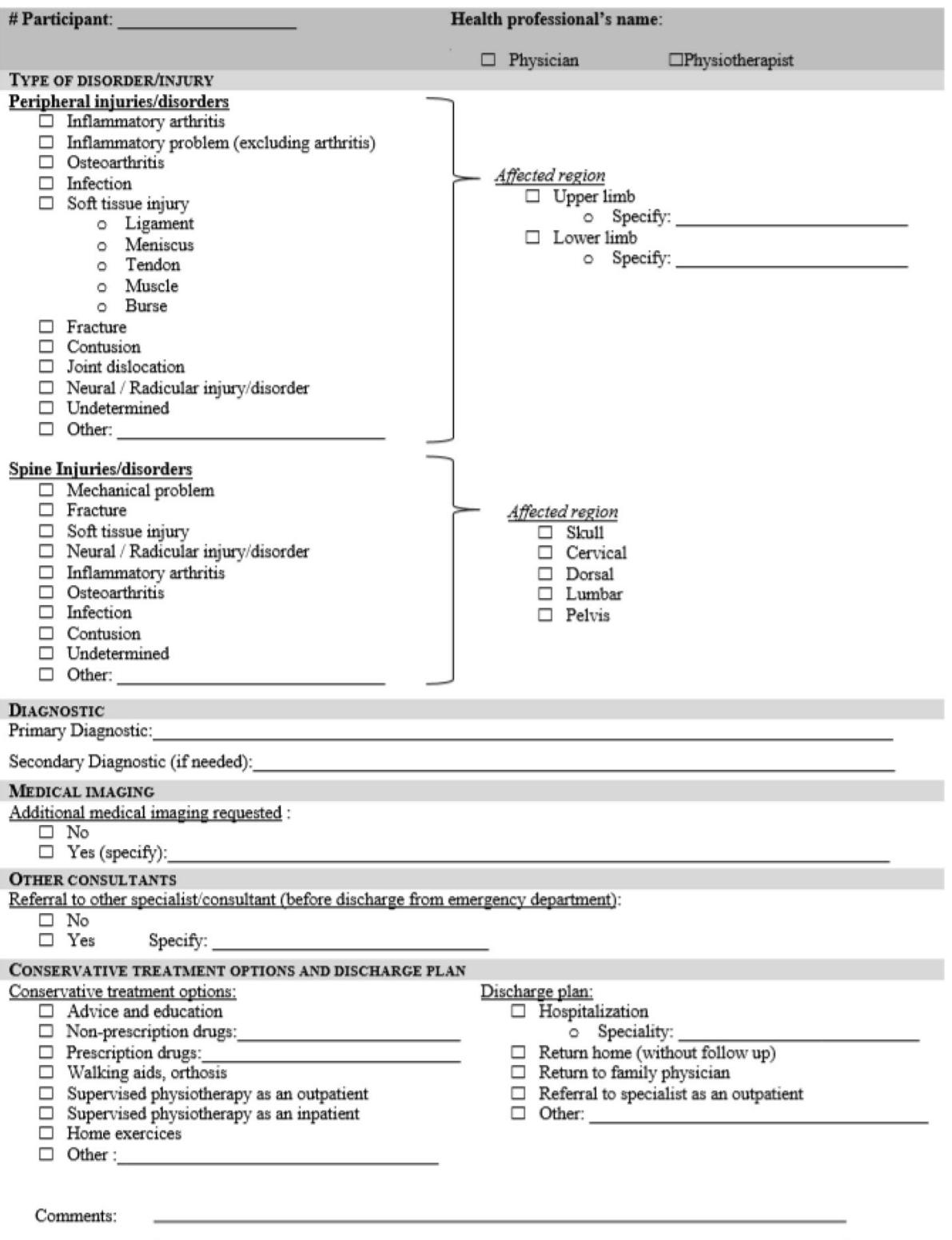

Fig. 2 Standardized Evaluation Form

\section{Abbreviations}

APP: Advanced practice physiotherapy; DASH: Disability of the Arm, Shoulder and Hand; ED: Emergency department; LEFS: Lower extremity functional scale; MSKD: Musculoskeletal disorders; NDI: Neck disability index; ODI: Oswestry disability index; PABAK: Prevalence and bias adjusted kappas; RCT: Randomized controlled trial; SF-36: 36-item Short Form Survey Questionnaire; VSQ-9: 9-item Visit-Specific Satisfaction Questionnaire; K: Cohen's Kappa

\section{Acknowledgments}

F. Desmeules is a CIHR and FROS research scholar. K. Perreault is a FROS research scholar.

\section{Authors' contributions}

Concept/idea/research design: EM, MM, KP, JSR, AA, EG, LC, VL, SD, BH, MA, NF, DP, FD. Writing: EM, MM, KP, JSR, AA, EG, LC, VL, SD, BH, MA, NF, DP, FD. Data collection: $M M, F D, E G, B H, E M, ~ M A$. Data analysis: EM, FD, VL, SD. Project management: FD, EM. Fund procurement: EM, MM, KP, JSR, AA, EG, LC, VL, SD, BH, MA, NF, DP, FD. Providing facilities/equipment: FD, EG, NF, MA. Providing institutional liaisons: $F D$, KP, MA, EG. Clerical/secretarial support: EM, FD, VL. Consultation (including review of manuscript before submitting): EM, MM, KP, JSR, AA, EG, LC, VL, SD, BH, $M A, N F, D P, F D$. All authors read and approved the final manuscript.

\section{Funding}

This project was funded by the Canadian MSK Rehab Research Network, the Québec Rehabilitation Research Network and the Physiotherapy Foundation 
of Canada. The funding bodies were not involved in the design of the study, data collection, analysis, interpretation of data and in writing the manuscript.

\section{Availability of data and materials \\ Not applicable}

\section{Ethics approval and consent to participate}

All participants signed a consent form prior to entering the study. This study was approved by the Research Ethics Boards of Maisonneuve-Rosemont Hospital and the Jewish General hospital.

\section{Consent for publication}

Not applicable

\section{Competing interests}

The authors declare that they have no competing interests.

\section{Author details}

${ }^{1}$ Maisonneuve-Rosemont Hospital Research Center, University of Montreal Affiliated Research Center, Montréal, Québec, Canada. ${ }^{2}$ CIUSSS Est-de-l'Île-de-Montréal, Québec, Canada. ${ }^{3}$ Center for Interdisciplinary Research in Rehabilitation and Social Integration (CIRRIS), Québec, Québec, Canada. ${ }^{4}$ Departement of Rehabilitation, Faculty of Medicine, Laval University, Québec, Québec, Canada. ${ }^{5}$ Faculty of Health, Dalhousie University, Halifax, Canada. ${ }^{6}$ Université de Picardie Jules Verne, Amiens, France. ${ }^{7}$ School of Rehabilitation, Faculty of Medicine, University of Montréal, Montréal, Québec, Canada. ${ }^{8}$ CIUSSS Centre-Ouest-de-I'Tlle-de-Montréal, Québec, Canada. ${ }^{9}$ Ordre Professionnel de la Physiothérapie du Québec, Montréal, Québec, Canada. ${ }^{10}$ School of Rehabilitation, Faculty of Medicine, McMaster University, Hamilton, Ontario, Canada.

\section{Received: 14 June 2019 Accepted: 11 October 2019}

\section{Published online: 10 November 2019}

\section{References}

1. Commissaire à la santé et au bien-être. Apprendre des meilleurs: Étude comparative des urgences du Québec. Gouvernement du Québec; 2016. p. 107

2. Canadian Institute for Health Information. How Canada compares: results from the commonwealth fund's 2016 international health policy survey of adults in 11 countries - accessible report. Ottawa, ON: ClHI; 2017.

3. Bombardier C HG, Mosher D. The Impact of Arthritis in Canada: Today and Over the Next 30 Years was prepared by the Arthritis Alliance of Canada.

4. Childs JD, Whitman JM, Sizer PS, Pugia ML, Flynn TW, Delitto A. A description of physical therapists' knowledge in managing musculoskeletal conditions. BMC Musculoskelet Disord. 2005;6:32.

5. Desmeules F, Roy JS, MacDermid JC, Champagne F, Hinse O, Woodhouse $\sqcup$. Advanced practice physiotherapy in patients with musculoskeletal disorders: a systematic review. BMC Musculoskelet Disord. 2012;13:107.

6. Desmeules F, Toliopoulos P, Roy JS, Woodhouse LJ, Lacelle M, Leroux M, et al. Validation of an advanced practice physiotherapy model of care in an orthopaedic outpatient clinic. BMC Musculoskelet Disord. 2013;14:162.

7. Aiken AB, Atkinson M, Harrison MM, Hope J. Reducing hip and knee replacement wait times: an expanded role for physiotherapists in orthopedic surgical clinics. Healthc Q. 2007:10(2):88-91 6.

8. Kersten PMK, Lattimer V, George S, Breton A, Ellis B. Physiotherapy extended scope of practice-who is doing what and why? Physiotherapy. 2007;93:235-42.

9. Kilner $\mathrm{E}$. What evidence is there that a physiotherapy service in the emergency department improves health outcomes? A systematic review. J Health Serv Res Policy. 2011;16:51-8.

10. Li LC, Westby MD, Sutton E, Thompson M, Sayre EC, Casimiro L. Canadian physiotherapists' views on certification, specialisation, extended role practice, and entry-level training in rheumatology. BMC Health Serv Res. 2009;9:88

11. McPherson KKP, George S, Lattimer V, Breton A, Ellis B, Kaur D, Frampton G. A systematic review of evidence about extended roles for allied health professionals. J Health Serv Res Policy. 2006;11:240-7.

12. McClellan CM, Cramp F, Powell J, Benger JR. Extended scope physiotherapists in the emergency department: a literature review. Phys Ther Rev. 2010;15(2):106-11.
13. Guengerich MB, Kim Cotton, Susan Mancuso, Sam. Emergency department primary contact physiotherapists improve patient flow for musculoskeletal patients. Int J Therapy Rehabilitation 2013;20(8):396-402.

14. Taylor N, Norman E, Roddy L, Tang C, Pagram A, Hearn K. Primary contact physiotherapy in emergency departments can reduce Iwnght of stay for patients with peripheral musculoskeletal injuries compared to secondary contact physiotherapy: a prospective non-randomised controlled trial. Physiotherapy. 2011:107-14.

15. Sayer JM, Kinsella RM, Cary BA, Burge AT, Kimmel LA, Harding P. Advanced musculoskeletal physiotherapists are effective and safe in managing patients with acute low back pain presenting to emergency departments. Aust Health Rev. 2017;42(3):321-6.

16. Lau PM, Chow DH, Pope MH. Early physiotherapy intervention in an accident and emergency department reduces pain and improves satisfaction for patients with acute low back pain: a randomised trial. Aust J Physiother. 2008;54(4):243-9.

17. Richardson B, Shepstone L, Poland F, Mugford M, Finlayson B, Clemence N. Randomised controlled trial and cost consequences study comparing initial physiotherapy assessment and management with routine practice for selected patients in an accident and emergency department of an acute hospital. Emerg Med J. 2005;22(2):87-92.

18. McClellan CM, Greenwood R, Benger JR. Effect of an extended scope physiotherapy service on patient satisfaction and the outcome of soft tissue injuries in an adult emergency department. Emerg Med J. 2006;23:384-7.

19. McClellan CM, Cramp F, Powell J, Benger JR. A randomised trial comparing the clinical effectiveness of different emergency department healthcare professionals in soft tissue injury management. BMJ Open. 2012;2:e001092.

20. Matifat E, Mequignon M, Cunningham C, Blake C, Fennelly O, Desmeules F. Benefits of Musculoskeletal Physicial Therapy in Emergency Departments: A Systematic Review. Physical Therapy. 2019;99:1150-66.

21. McHorney CA, Ware JE, Jr., Lu JF, Sherbourne CD. The MOS 36-item shortform health survey (SF-36): III. Tests of data quality, scaling assumptions, and reliability across diverse patient groups. Med Care 1994;32(1):40-66.

22. Ware JE Jr, Sherbourne CD. The MOS 36-item short-form health survey (SF-36). I. Conceptual framework and item selection. Med Care. 1992;30(6):473-83.

23. Brazier JE, Harper R, Munro J, Walters SJ, Snaith ML. Generic and conditionspecific outcome measures for people with osteoarthritis of the knee. Rheumatology (Oxford). 1999;38(9):870-7.

24. MacDermid JC, Walton DM, Avery S, Blanchard A, Etruw E, McAlpine C, et al. Measurement properties of the neck disability index: a systematic review. J Orthop Sports Phys Ther. 2009;39(5):400-17.

25. Fairbank JC, Pynsent PB. The Oswestry disability index. Spine (Phila Pa 1976). 2000;25(22):2940-52 discussion 52.

26. Angst F, Schwyzer HK, Aeschlimann A, Simmen BR, Goldhahn J. Measures of adult shoulder function: Disabilities of the Arm, Shoulder, and Hand Questionnaire (DASH) and its short version (QuickDASH), Shoulder Pain and Disability Index (SPADI), American Shoulder and Elbow Surgeons (ASES) Society standardized shoulder assessment form, Constant (Murley) Score (CS), Simple Shoulder Test (SST), Oxford Shoulder Score (OSS), Shoulder Disability Questionnaire (SDQ), and Western Ontario Shoulder Instability Index (WOSI). Arthritis care Res. 2011:63(Suppl 11):S174-88.

27. Roy JS, MacDermid JC, Woodhouse LJ. Measuring shoulder function: a systematic review of four questionnaires. Arthritis Rheum. 2009:61(5):623-32

28. Binkley JM, Stratford PW, Lott SA, Riddle DL. The lower extremity functional scale (LEFS): scale development, measurement properties, and clinical application. North American Orthopaedic rehabilitation research network. Phys Ther. 1999;79(4):371-83.

29. Rene F, Casimiro L, Tremblay M, Brosseau L, Chea P, Letourneau L, et al. [In process citation]. Physiotherapy Canada Physiotherapie Canada 2011;63(2):249-255.

30. Rene F, Casimiro L, Tremblay M, Brosseau L, Lefebvre A, Beaudouin M, et al. In process citation. Physiotherapy Canada Physiotherapie Canada. 2011; 63(2):242-8.

31. Kennedy DM, Robarts S, Woodhouse L. Patients are satisfied with advanced practice physiotherapists in a role traditionally performed by orthopaedic surgeons. Physiother Can. 2010;62(4):298-305.

32. Matifat E, Mequignon, M., Perreault, K., Roy, J.-S., Aiken, A., Gagnon, E. Carlesso, L., Lowry, V., Décary, S., Hamelin, B., Farley, N., Pelletier, D., Desmeules, F., editor Preliminary Results of an Advanced Practice Physiotherapy Model of care for Patients with Musculoskeletal Disorders Presenting to an Emergency Department APTA Combined Sections Meeting; 2018 January; USA: JOSPT. 
33. Razmjou H, Kramer JF, Yamada R. Intertester reliability of the McKenzie evaluation in assessing patients with mechanical low-back pain. J Orthop Sports Phys Ther. 2000;30(7):368-83 discussion 84-9.

34. Razmjou H, Robarts S, Kennedy D, McKnight C, Macleod AM, Holtby R.

Evaluation of an advanced-practice physical therapist in a specialty shoulder clinic: diagnostic agreement and effect on wait times. Physiother Can. 2013; 65(1):46-55.

35. Sim J, Wright CC. The kappa statistic in reliability studies: use, interpretation, and sample size requirements. Phys Ther. 2005;85(3):257-68.

36. Aiken $A B, M c C o l l ~ M A$. Diagnostic and treatment concordance between a physiotherapist and an orthopedic surgeon--a pilot study. J Interprof Care. 2008;22(3):253-61.

37. Moore JH, Goss DL, Baxter RE, DeBerardino TM, Mansfield LT, Fellows DW et al. Clinical diagnostic accuracy and magnetic resonance imaging of patients referred by physical therapists, orthopaedic surgeons, and nonorthopaedic providers. J Orthop Sports Phys Ther. 2005;35(2):67-71.

38. Decary S, Fallaha M, Pelletier B, Fremont P, Martel-Pelletier J, Pelletier JP, et al. Diagnostic validity and triage concordance of a physiotherapist compared to physicians' diagnoses for common knee disorders. BMC Musculoskelet Disord. 2017;18(1):445.

39. Ball S, Walton $\mathrm{K}$, Hawes S. Do emergency department physiotherapy practitioner's, emergency nurse practitioners and doctors investigate, treat and refer patients with closed musculoskeletal injuries differently? Emerg Med J. 2007:24:185-8.

40. Canadian Institute for Health Information. Pan-Canadian trends in the prescribing of opioids, 2012 to 2016. Ottawa, ON: CIHl; 2017.

41. Busse JW, Craigie S, Juurlink DN, Buckley DN, Wang L, Couban RJ, et al. Guideline for opioid therapy and chronic noncancer pain. CMAJ. 2017: 189(18):E659-E66.

42. Deslauriers S, Raymond MH, Laliberte M, Lavoie A, Desmeules F, Feldman $D E$, et al. Access to publicly funded outpatient physiotherapy services in Quebec: waiting lists and management strategies. Disabil Rehabil. 2017; 39(26):2648-56.

\section{Publisher's Note}

Springer Nature remains neutral with regard to jurisdictional claims in published maps and institutional affiliations.

Ready to submit your research? Choose BMC and benefit from:

- fast, convenient online submission

- thorough peer review by experienced researchers in your field

- rapid publication on acceptance

- support for research data, including large and complex data types

- gold Open Access which fosters wider collaboration and increased citations

- maximum visibility for your research: over $100 \mathrm{M}$ website views per year

At $\mathrm{BMC}$, research is always in progress.

Learn more biomedcentral.com/submissions 